\title{
Correspondence
}

\section{Neuromuscular blockade and ventilatory failure after cyclosporine}

To the Editor,

In the retrospective study by Sidi et al. ${ }^{1}$ we feel that the authors fail to support their conclusions adequately. They reported incidents of prolonged neuromuscular blockade and ventilatory failure after renal transplantation - eight patients out of 65 over a one-year period. They conclude that the administration of $5 \mathrm{mg} \cdot \mathrm{kg}^{-1}$ cyclosporine iv contributed to this complication. As support for their argument they state that three of the eight patients with respiratory failure received cyclosporine $(P<0.05$ by Fisher's exact test). They quote the publications by Gramstad et al. and Fragen et al. - work performed in an animal model (cats) and in vitro, but not yet confirmed in humans. In the other five they were unable to offer an explanation, disregarding the drugs used for premedication.

Their routine premedication included ranitidine $150 \mathrm{mg}$ and 20 patients received diazepam 5-10 mg. Was there any correlation between the patients with prolonged neuromuscular blockade and respiratory failure and premedication with diazepam?

Diazepam has muscle relaxant properties ${ }^{2}$ and an elimination half-life of $20-40 \mathrm{hr}$ with active metabolites which have an even longer half-life. ${ }^{2}$ It is also highly protein bound and patients with chronic renal failure have an increased unbound fraction. ${ }^{2.3}$ Further, histamine $\mathrm{H}_{2}$ receptor antagonists inhibit the oxidative metabolism of diazepam. ${ }^{2}$

Despite the routine infusion of $5 \mathrm{mg} \cdot \mathrm{kg}^{-1}$ of cyclosporine commenced one hour prior to surgery and given over four hours, prolonged neuromuscular blockade and respiratory failure is an extremely uncommon complication in our renal transplant patients. We reviewed all our renal transplants performed in 1989 (104 patients) and 1990 (107 patients). In the 211 transplants, all but six patients received cyclosporine. Our routine does not include premedicant drugs; induction is with thiopentone and succinylcholine and maintenance with oxygen, nitrous oxide, halothane and fentanyl $1-2 \mu \mathrm{g} \cdot \mathrm{kg}^{-1}$. A peripheral nerve stimulator is used intraoperatively. Reversal is with neostigmine and atropine. When the patient is breathing spontaneously, is fully awake, and neuromusuclar function is adequate as shown by peripheral nerve stimulation, the trachea is extubated and he is returned to the renal unit.
Three of our 211 cases needed postoperative pulmonary ventilation. Two because of acute pulmonary oedema and only one because of muscular weakness and depressed respiration. This was the only patient to receive diazepam, $10 \mathrm{mg}$ as premedication, contrary to our protocol. $\mathrm{He}$ required four hours of postoperative ventilation before he could be safely extubated.

In conclusion we feel that cyclosporine has been unjustifiably implicated in the cases of prolonged neuromuscular blockade and ventilatory failure. In the three patients in the study by Sidi et al. other causes for respiratory failure such as the use of diazepam and ranitidine for premedication could well have played a role.

V. Kadieva MD

P. V. van Heerden FFARCS(I)

A. Roux FFA(SA)

L. Friedman MD

D. F. Morrell FFA(SA)

Department of Anaesthesia

Johannesburg Hospital and

University of the Witwatersrand

Private Bag X39,

Johannesburg 2000, South Africa

\section{REFERENCES}

1 Sidi A, Kaplan RF, Davis RF. Prolonged neuromusuclar blockade and ventilatory failure after renal transplantation and cyclosporine. Can J Anaesth 1990; 37: 543-8.

2 Wood $M$. Intravenous anesthetic agents. In: Wood M, Wood AJJ (Eds.). Drugs and Anesthesia. Baltimore: Williams and Wilkins 1990: 198-9.

3 Sladen $N$. Perioperative management of the patient with renal failure. In: ASA Manual. American Society of Anesthesiologists, 1988; 172: 1-3.

\section{REPLY}

In response to the comments, we report additional information on the premedications used for the patients in our retrospective study, who had undergone kidney transplantation: According to Fisher's exact probability test, the incidence of respiratory failure did not differ among those patients who did and did not receive tranquillizers. In fact, none of the patients who presented with respiratory failure received diazepam or midazolam (Table).

Of 211 patients reported by Kadieva et al., two needed postoperative ventilation because of pulmonary oedema. Although we are not given information on the causes of pulmonary oedema in these particular patients, it may have been caused by respiratory failure resulting from aspiration or 
TABLE Preanaesthetic medications in patients who did and did not suffer respiratory failure after kidney transplantation

\begin{tabular}{lll}
\hline & $\begin{array}{l}\text { Patients without } \\
\text { respiratory failure } \\
(n=57)\end{array}$ & $\begin{array}{l}\text { Patients with } \\
\text { respiratory failure } \\
(n=8)\end{array}$ \\
\hline Diazepam & 20 & 0 \\
Midazolam & 5 & 0 \\
Lorazepam & 2 & 1 \\
Phenergan & 3 & 1 \\
\hline
\end{tabular}

negative pressure-type oedema due to respiratory depression or muscle weakness. Further, a thorough retrospective analysis of the course of the 211 patients should include data on all possible causes of respiratory failure, such as narcotics. Without this information, the conclusion that diazepam caused respiratory depression is only speculative. Another possible explanation for respiratory depression in this clinical setting is that it may result from a combination of drugs, for example, diazepam plus cyclosporine. Finally, it is not surprising that effects of operation and neuromuscular blockade differ between patients who received halothane and those who received isoflurane.' Isoflurane, compared with halothane followed by vecuronium, has been shown clinically to augment neuromuscular blockade. ${ }^{2}$

Avner Sidi MD

Department of Anesthesiology

University of Florida College of Medicine

Gainesville, Florida

\section{REFERENCES}

1 Sidi A, Kaplan RF, Davis RF. Prolonged neuromuscular blockade and ventilatory failure after renal transplantation and cyclosporine. Can J Anesth 1990; 37: 543-8.

2 Rupp SM, Miller RD, Gencarelli PJ. Vecuroniuminduced neuromuscular blockade during enflurane, isoflurane, and halothane anesthesia in humans. Anesthesiology 1984; 60: 102-5.

\section{Time-cycled inverse ratio ventilation}

To the Editor:

After reading with interest the article by Drs. Tweed and Lee $^{l}$ on time-cycled inverse ratio ventilation (TC-IRV) during anaesthesia, we would like to emphasize several points which require clarification.

Our group uses IRV in a time-cycled volume-controlled mode with a constant inspiratory flow adjusted to deliver and end-inspiratory plateau of about $0.5 \mathrm{sec}$ for several years. ${ }^{2,3}$ Tweed and Lee have used the term time-cycled IRV to distinguish this mode from pressure-controlled IRV (PC-IRV). However, PC-IRV as introduced by Lachmann et al. ${ }^{4}$ is also a time-cycled form of ventilation because inspiratory and expiratory time are preset at the ventilator (by respiratory rate and inspiratory/expiratory (I/E) - ratio) and are not influenced by lung mechanics. In PC-IRV the inspiratory airway pressure is adjusted at the ventilator allowing tidal volume to vary according to changes of lung mechanics. This is the only difference to volume-controlled IRV (VC-IRV) where tidal volume is constant and airway pressure follows the changes in lung impedance.

Several reports have stressed the importance of air trapping and occult PEEP ("auto PEEP," "intrinsic PEEP") mechanisms due to a short expiratory time. ${ }^{3,5,6}$ This gain in end-expiratory lung volume is basically governed by the ratio of expiratory time ( $\mathrm{Te}$ ) to the time constant of the lungs (tau). In the study of Tweed and Lee the shortest expiratory time (respiratory rate $=10 \cdot \mathrm{min}^{-1}, \mathrm{Te}=23 \%$ ) of $1.4 \mathrm{sec}$ was far above the time constant calculated from the measured compliance and expiratory resistance $(0.05$ $\times 11=0.55 \mathrm{sec})$. Although the authors did not estimate the intrinsic PEEP by an expiratory clamping manoeuvre and did not look for the presence of any end-expiratory flow we agree that according to the lung function of the studied patients there should be only a negligible intrinsic PEEP under the investigated conditions.

As the improvement in oxygen transfer is attributed to the presence of considerable intrinsic PEEP, ${ }^{3,6}$ it is not surprising that Tweed and Lee could not see any changes in this aspect. Using higher respiratory rates (15-20. $\min ^{-1}$ ), as we do frequently in intensive care patients, a similar designed investigation would probably result in a more optimistic view of IRV during anesthesia.

Christian Putensen MD

Marcel Baum

Christoph Hörman MD

Werner Lingnau MD

Clinic for Anesthesia and General Intensive

Care Medicine

University of Innsbruck

A-6020 Innsbruck, Austria

\section{REFERENCES}

1 Tweed WA, Lee TL. Time-cycled inverse ratio ventilation does not improve gas exchange during anaesthesia. Can J Anaesth 1991; 38: 331-7.

2 Baum M, Benzer H, Mutz N, Pauser G, Toncar $L$. Inversed ratio ventilation. Anaesthesist 1980; 29: 592-7.

3 Koller W, Putensen Ch, Mutz N, Benzer H. Cardiopulmonal sequelae of volume constant inversed ratio ventilation (IRV). Intensive Care Med 1986; 12: 181.

4 Lachmann B, Haendly B, Schultz H, Johnson B. Improved oxygenation, $\mathrm{CO}_{2}$ elimination, compliance and decreased barotrauma following changes from volume-generated PEEP ventilation with inspiratory/expiratory (I/E) ratio of 